\title{
PERCEPÇÃO DOS AGRICULTORES DE CAJAZEIRAS NA PARAÍBA, QUANTO AO USO DA ÁGUA DE CHUVA PARA FINS POTÁVEIS
}

\author{
J. D. de S. Barros ${ }^{1}$, S. C. Torquato $^{1}$, D. C. F. de Azevedo ${ }^{1}$,F. G. de A. Batista ${ }^{1}$ \\ ${ }^{1}$ Programa de Pós-graduação em Recursos Naturais; Universidade Federal de Campina Grande - UFCG \\ deomarbarros@gmail.com - silvana.torquato@hotmail.com -fabioelara@gmail.com -olscargeo@yahoo.com.br
}

Artigo submetido em março/2012 e aceito em abril/2013

\section{RESUMO}

A carência de água de qualidade para abastecimento humano, no Semiárido brasileiro, contribui para reduzir a qualidade da vida desta população, dificultando assim sua própria fixação no campo. Neste sentido, a construção de cisternas nas comunidades rurais constitui uma solução viável para a convivência destas populações com o Semiárido, ao contribuir com a permanência das famílias no meio rural pela oferta de água potável para consumo humano. Neste sentido, o presente trabalho tem o objetivo de diagnosticar o perfil socioeconômico de agricultores assentados do município de Cajazeiras, bem como avaliar a percepção dos agricultores quanto ao uso da água de chuva captada em cisternas. A referida pesquisa foi realizada no período de 25 de abril a 13 de maio de 2011, contendo uma amostra de 20 famílias. Foi elaborado um questionário sócio-ambiental semi-estruturado e aplicado, na forma de entrevistas em visitas feitas nos assentamentos, seguido de observações diretas de todas as condições locais direcionadas ao foco do trabalho. Os resultados obtidos indicam que as pessoas que vivem nesta localidade apresentam uma escolaridade baixa, utilizam água de beber proveniente de cisternas, adotam barreiras sanitárias para evitar a contaminação da água. Todas as entrevistadas afirmaram que as cisternas contribuíram para melhorar, a qualidade de vida das famílias relacionadas a melhorias significativas na saúde familiar.

PALAVRAS-CHAVE: Semiárido, cisternas, assentamentos, saúde familiar.

\section{PERCEPTION OF FARMERS CAJAZEIRAS IN PARAÍBA, ON THE USE OF RAINWATER FOR POTABLE PURPOSES}

\begin{abstract}
The lack of quality water for human supply, the Brazilian semiarid, helps to reduce the quality of life of this population, thus hindering his own fixation on the field. In this sense, the construction of cisterns in rural communities is a viable solution for the coexistence of these populations with Semiarid by contributing to the permanence of families in rural areas for the provision of potable water for human consumption. In this sense, the present work aims to diagnose the socioeconomic profile of farmers settled the city of Cajazeiras, as well as evaluating the perception of farmers regarding the use of captured rainwater in cisterns. That research was
\end{abstract}

carried out from April 25 to May 13, 2011, containing a sample of 20 families. A questionnaire was developed socio-environment semi-structured and implemented in the form of interviews on visits made in the settlements, followed by direct observations of local conditions all directed to focus the work. The results indicate that people who live in this area have a low educational level, use drinking water from cisterns, adopt sanitary barriers to prevent water contamination. All interviewees stated that the tanks have contributed to improving the quality of life of families related to significant improvements in family health.

KEY-WORDS: Semiarid, tanks, settlements, family health. 


\section{PERCEPÇÃO DOS AGRICULTORES DE CAJAZEIRAS NA PARAÍBA, QUANTO AO USO DA ÁGUA DE CHUVA PARA FINS POTÁVEIS}

\section{INTRODUÇÃO}

O uso sustentável da água é um desafio para a sociedade contemporânea, tendo em vista a necessidade de conciliar as atividades antrópicas com a conservação ambiental, procurando assim mitigar os impactos nos ecossistemas aquáticos. A demanda por água é atualmente uma realidade global, neste sentido o seu uso racional é de interesse crescente na sociedade civil e nos órgãos gestores que procuram soluções tecnológicas viáveis para fornecimento de água para a população. Essa busca de alternativas é essencial tendo em vista o aumento populacional, as mudanças climáticas globais e a escassez de água nas regiões áridas e semiáridas do planeta (TAVARES, 2009).

Segundo Neves et al. (2010), o semiárido brasileiro compreende todos os estados do Nordeste além da região norte do Estado de Minas Gerais e nordeste do Espírito Santo, abrangendo uma área de $969.584,4 \mathrm{Km}^{2}$, sua população estimada é de 21 milhões de pessoas, correspondendo a $11 \%$ da população brasileira constituindo a região semi-árida mais populosa do planeta.

Nesta região, a presença de períodos prolongados de baixa pluviosidade é constante, concomitantemente a isso durante os períodos de estiagem ocorre um aumento significativo da temperatura provocando assim altos índices de evaporação da água presente nos reservatórios (SANTOS e SILVA, 2009). A variação nos índices pluviométricos nesta região é um fato, mas, apesar da irregularidade e má distribuição nas ocorrências de chuvas, o semiárido no Brasil é uma das regiões mais úmidas (média de $750 \mathrm{~mm}$ ) em relação a outras regiões semiáridas do planeta. (SILVA et al., 2006).

O semiárido nordestino, devido à escassez de água, apresenta baixa disponibilidade deste recurso, constituindo assim uma relevante limitação para o desenvolvimento socioeconômico da população rural. Além disso, o acesso limitado à água provoca impactos negativos na saúde da família (XAVIER, 2010).

Nas últimas décadas puderam ser observadas mudanças relativas ao paradigma de combate a seca, pois, se anteriormente a luta era para combater a seca, agora a ênfase se volta para a convivência com o semiárido, tendo em vista que se adotando políticas públicas e práticas sustentáveis esta convivência torna-se uma realidade. Neste contexto, a captação da água de chuva torna-se uma alternativa viável que somada a outras políticas públicas, contribuiu com o desenvolvimento sustentável da região, sendo a construção de cisternas uma destas alternativas com melhor relação custo-benefício. Neste sentido, a instalação de sistemas de captação de água de chuva e seu uso racional representa uma contribuição efetiva para o acesso equitativo ao uso da água por todos os cidadãos (PONTES e MACHADO, 2009).

Uma experiência significativa é o "Programa de Formação e Mobilização para Convivência com o Semi-árido: Um Milhão de Cisternas Rurais (P1MC)", que tem demonstrado ser uma alternativa relevante para abastecer as famílias com água de boa qualidade, minimizando assim os problemas relacionados à falta de água, tendo em vista que o sistema de captação de água de chuva através das cisternas representa uma tecnologia acessível e de baixo custo capaz de armazenar grandes volumes de água durante o ano. No entanto, faz-se necessária a adoção de 
medidas de higiene no manejo desta água para que ela não venha constituir foco de contaminação microbiológica (SILVA et al., 2006).

De acordo com Bezerra et al. (2010) a utilização de cisternas, no semiárido brasileiro, promove benefícios significativos tendo em vista o beneficiamento de famílias ao facilitar o acesso a água em quantidade e qualidade, potencializando melhoras significativas na saúde e nas condições de vida da população assistida.

Diante do exposto, observamos a importância do uso racional de água. Dessa forma, devemos pensar em desenvolver tecnologias que permitam a captação, armazenamento e preservação da água, com tecnologias ambientalmente corretas, tais como a captação de água de chuva por um sistema de cisternas de placas. Neste sentido, o presente trabalho tem o objetivo de diagnosticar o perfil socioeconômico, bem como avaliar a percepção ambiental sobre o uso sustentável da água de agricultores assentados do município de Cajazeiras, do estado da Paraíba.

\section{METODOLOGIA}

\section{Caracterização da área de estudo}

O município de Cajazeiras está localizado no estado da Paraíba, sendo o mesmo pertencente à Mesorregião do Sertão Paraibano. Localiza-se a oeste da capital do estado, João Pessoa, com cerca de $475 \mathrm{Km}$ de distância. Ocupa uma área de $586.275 \mathrm{~km}^{2}$, com população de 58.437 habitantes, segundo o Instituto Brasileiro de Geografia e estatística, em 2010. O clima é de semi-árido quente e seco, com uma temperatura média anual entre $23^{\circ} \mathrm{C}$ e $30^{\circ} \mathrm{C}$, e vegetação é do tipo caatinga, caracterizada pela escassez de água.

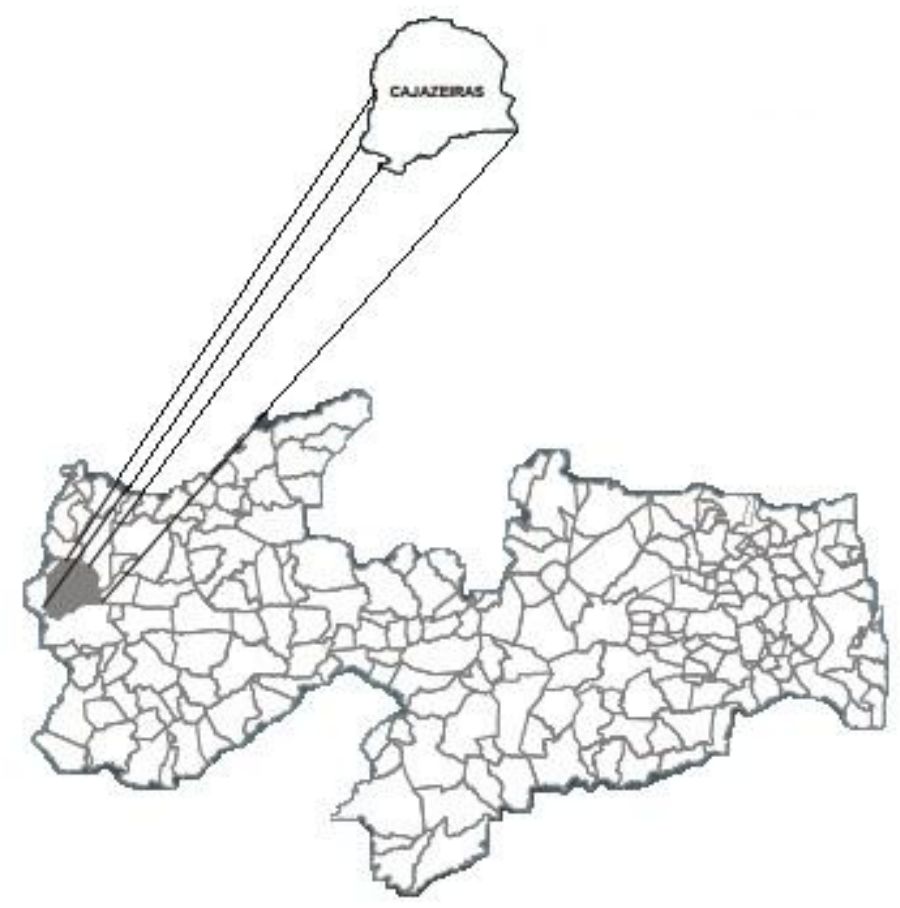

Figura 1. Localização do Município de Cajazeiras no Estado da Paraíba 


\section{Diagnóstico do contexto social, econômico e cultural}

Para se obter uma visão geral sobre o padrão social e econômico, bem como a percepção da relação água-saúde-uso sustentável da água, foi elaborado um questionário sócio-ambiental semi-estruturado e aplicado, na forma de entrevistas, acompanhado de observações diretas de todas as condições locais direcionadas ao foco do trabalho.

\section{Classificação da Pesquisa}

Para a classificação da pesquisa, tomou-se como base a metodologia adotada por Silva (2001). Do ponto de vista da natureza a pesquisa é classificada como aplicada, em que se refere a conhecimentos para aplicação prática dirigidos à solução de problemas específicos. Quanto à forma de abordagem a pesquisa é classificada como quantitativa, a qual significa traduzir em números opiniões e informações para classificá-las e analisá-las. Do ponto de vista de seus objetivos a pesquisa pode ser classificada como exploratória, a qual envolve levantamento bibliográfico; entrevistas com pessoas que tiveram experiências práticas com o problema pesquisado; com relação aos procedimentos técnicos constituiu-se de um levantamento.

\section{Aplicação do Questionário}

A pesquisa foi realizada através de visitas aos assentamentos Frei Damião e Santo Antônio no período de 25 de abril a 13 de maio de 2011. Tendo como instrumento de pesquisa um questionário contendo questões objetivas e subjetivas, abordando os aspectos sócio-econômicos dos agricultores, usos da água de cisternas, origem da água utilizada pela família para beber e para higiene pessoal, armazenamento da água, formas de tratamento, entre outros.

A referida pesquisa foi realizada no período de 25 de abril a 13 de maio de 2011, contendo uma amostra de 20 famílias. Sendo que do total foram entrevistadas 13 famílias no assentamento Santo Antônio e 7 famílias do assentamento Frei Damião.

Incluíram-se no estudo todas as famílias dos assentamentos pesquisados, cujas casas estivessem abertas por ocasião da visita dos pesquisadores e que tivessem um responsável adulto disponível para responder o questionário, além de aceitar participar voluntariamente da pesquisa.

\section{RESULTADOS E DISCUSSÕES}

De acordo com os questionários respondidos foi traçado um perfil dos entrevistados. Os dados referentes ao sexo da população dos assentamentos Frei Damião e Santo Antônio, estão representados na Figura 1. 


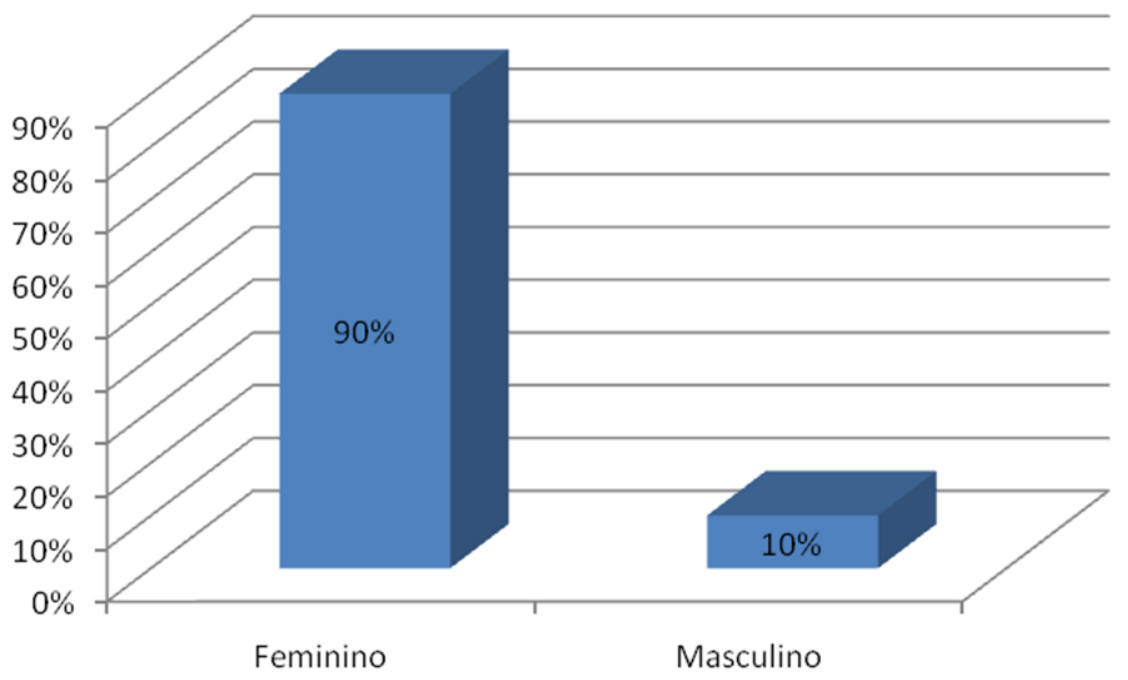

Figura 1 - Sexo da população dos assentamentos Frei Damião e Santo Antônio.

Após a analise dos dados verificou-se que $90 \%$ dos entrevistados são do sexo feminino. A aplicação do questionário deu-se nos períodos matutino e vespertino, nestes horários geralmente os homens estão no roçado o que justifica o número elevado de mulheres que participaram da pesquisa. Vásquez et al. (2008) realizando pesquisa com produtores orgânicos nestes dois assentamentos verificaram que $67 \%$ dos produtores são do sexo feminino.

A Figura 2 ilustra o grau de escolaridade da população dos assentamentos Frei Damião e Santo Antônio.

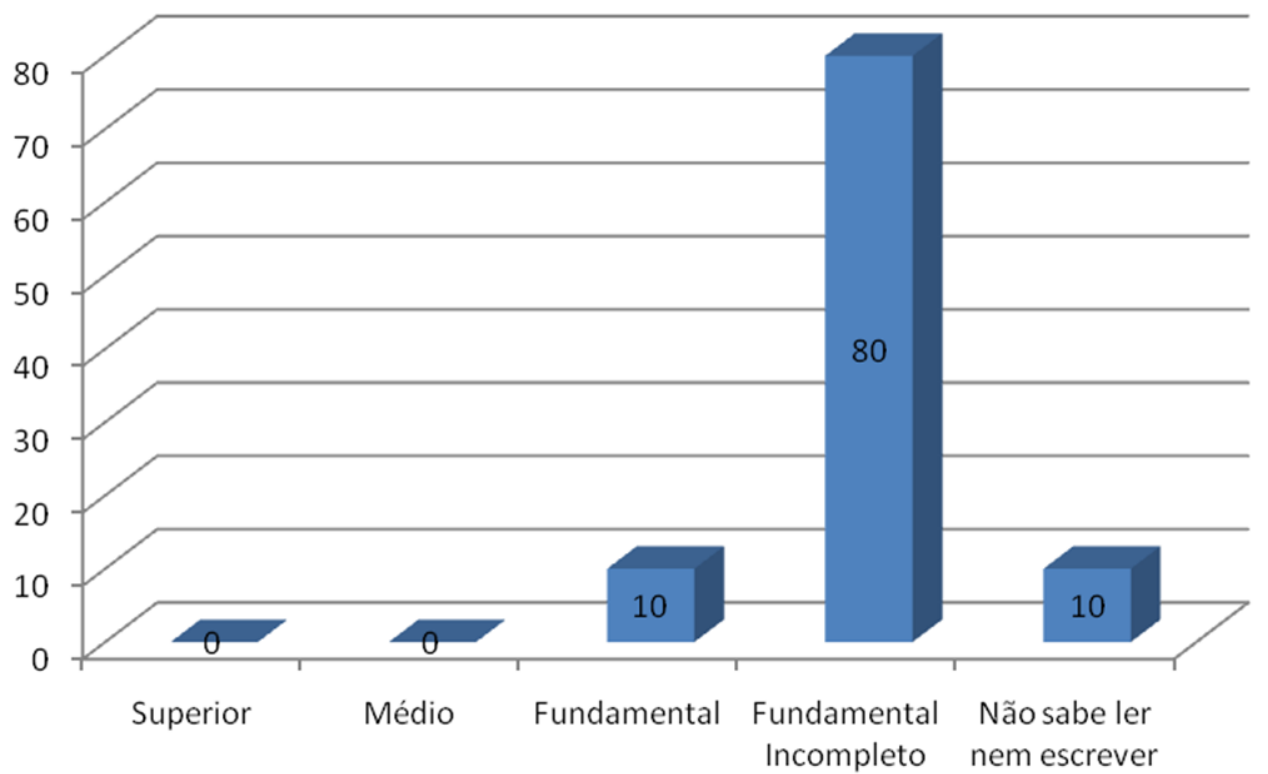

Figura 2 - Escolaridade da população dos assentamentos Frei Damião e Santo Antônio.

Com relação à escolaridade dos entrevistados, verificou-se que $80 \%$ possuem apenas o ensino fundamental incompleto, estes dados indicam que os agricultores pesquisados apresentam índices de analfabetismos inferiores aos estudos aqui referenciados, ao passo que como visto na figura acima os agricultores apresentaram alto índice no nível de escolaridade 
Ensino Fundamental Incompleto. Oltramari et al. (2002) em pesquisa realizada em Santa Catarina constataram que o nível médio de escolaridade dos agricultores pesquisados é o primeiro grau incompleto $(68,16 \%)$. Vásquez et al. (2008) pesquisaram o perfil dos produtores orgânicos nos assentamentos Frei Damião e Santo Antônio verificaram que $67 \%$ dos produtores não concluíram o Ensino Fundamental. Botto (2007) em trabalho realizado em Itaiçaba verificaram que 35\% dos chefes de família são analfabetos, assim como Tavares (2009), em pesquisa realizada do semiárido Paraibano, em três comunidades que tiveram índices de analfabetismo, variando entre 21 e $38 \%$.

Os produtores apresentam em média 47,3 anos de idade, vivem nas propriedades rurais a mais de 15 anos, desde o inicio do processo de assentamento. As famílias são compostas em média 4,6 pessoas por família. Todos os agricultores entrevistados têm na agricultura sua principal ocupação, $60 \%$ destes agricultores vendem geralmente uma parte de sua produção anual, $40 \%$ das famílias são beneficiadas do programa bolsa família e $50 \%$ das famílias pesquisadas têm em sua residência pelo menos uma pessoa aposentada.

Na Figura 3 estão apresentados os dados referentes a renda familiar da população dos assentamentos Frei Damião e Santo Antônio.

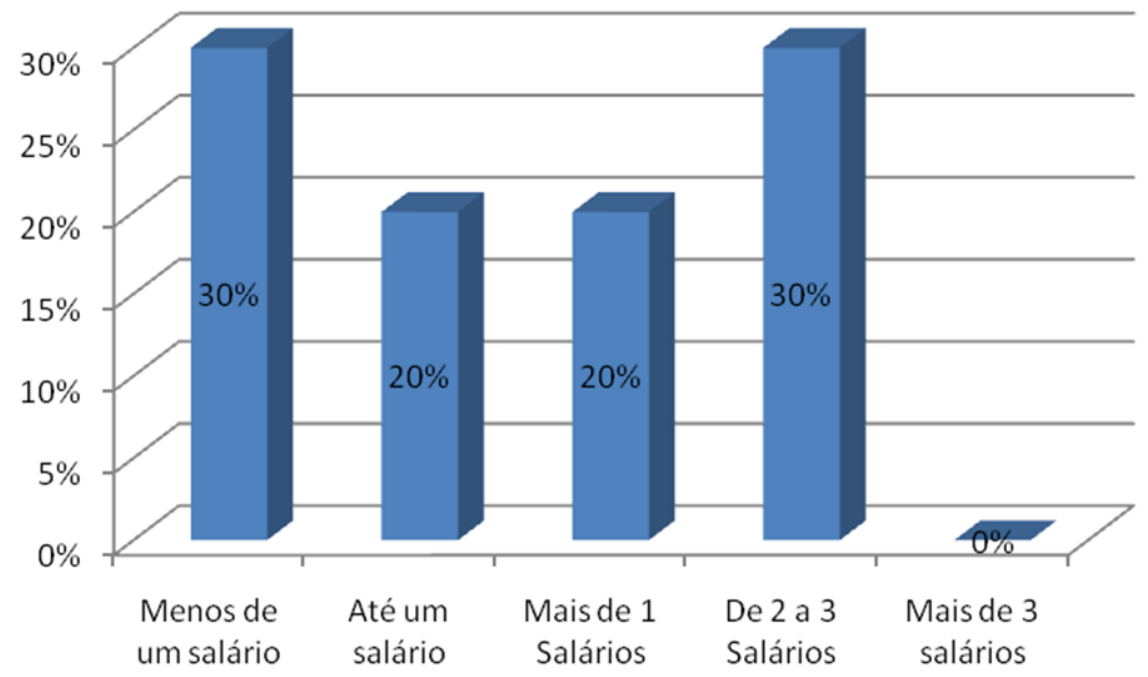

Figura 3 - Renda Familiar da população dos assentamentos Frei Damião e Santo Antônio.

Com relação à renda mensal da família, a pesquisa apontou um alto índice $(30 \%)$ de famílias que sobrevivem com menos de um salário por mês. Os resultados referentes à renda familiar dos agricultores dos assentamentos Frei Damião e Santo Antônio corroboram com os de Botto (2007), em que $40 \%$ das famílias possuem renda inferior a 1 (um) salário mínimo, bem como os de Tavares (2009) que constatou que entre $10 \%$ e $30 \%$ da população de três comunidades do semi-árido paraibano sobrevivem com menos de um salário mínimo por mês, o que resulta em famílias com condições de vida precárias.

O conjunto de dados referentes à origem da água de consumo da família (água para beber) dos agricultores dos assentamentos Frei Damião e Santo Antônio, estão representados na Figura 4. 


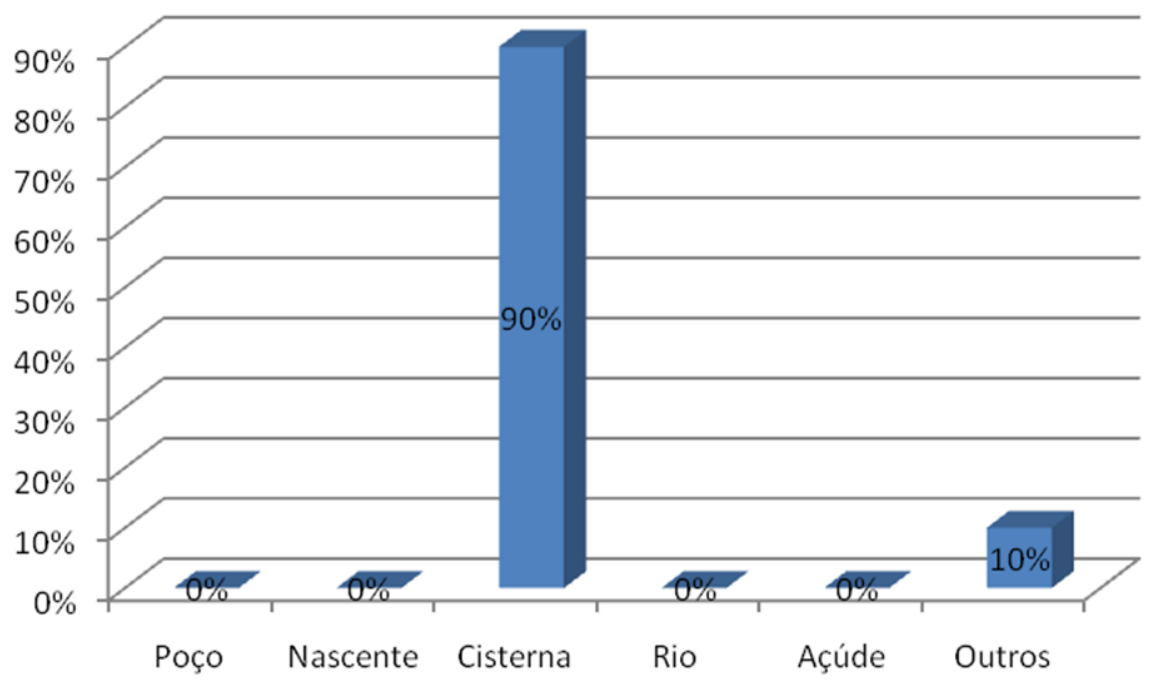

Figura 4 - Origem da água de consumo da família (água para beber).

Todas as residências visitadas possuem cisternas e água encanada proveniente de açúdes próximos da localidade. Com relação a origem da água que a família utiliza para beber, $90 \%$ dos agricultores pesquisados responderam que utilizam a água da cisterna para este fim. As pesssoas que não usam água da cisterna dar-se pelo fato das cisternas apresentarem vasamentos ou por considerar a água da cisterna impura, recorrendo assim ao consumo de água mineral. Estes resultados corroboram com os de Tavares (2009) em que relata que a maioria das famílias pesquisadas utilizam água proveniente de cisternas e poços para higiene pessoal e limpeza. Sendo $67,5 \%$ do uso de águas de cisternas utilizadas para beber e cozinhar, esta situação ratifica a necessidade de monitoramento sistemático da qualidade da água de cisterna através de programas governamentais.

Na Figura 5 são apresentados dados de pesquisa relacionados ao Armazenamento de água de beber da população dos assentamentos Frei Damião e Santo Antônio.

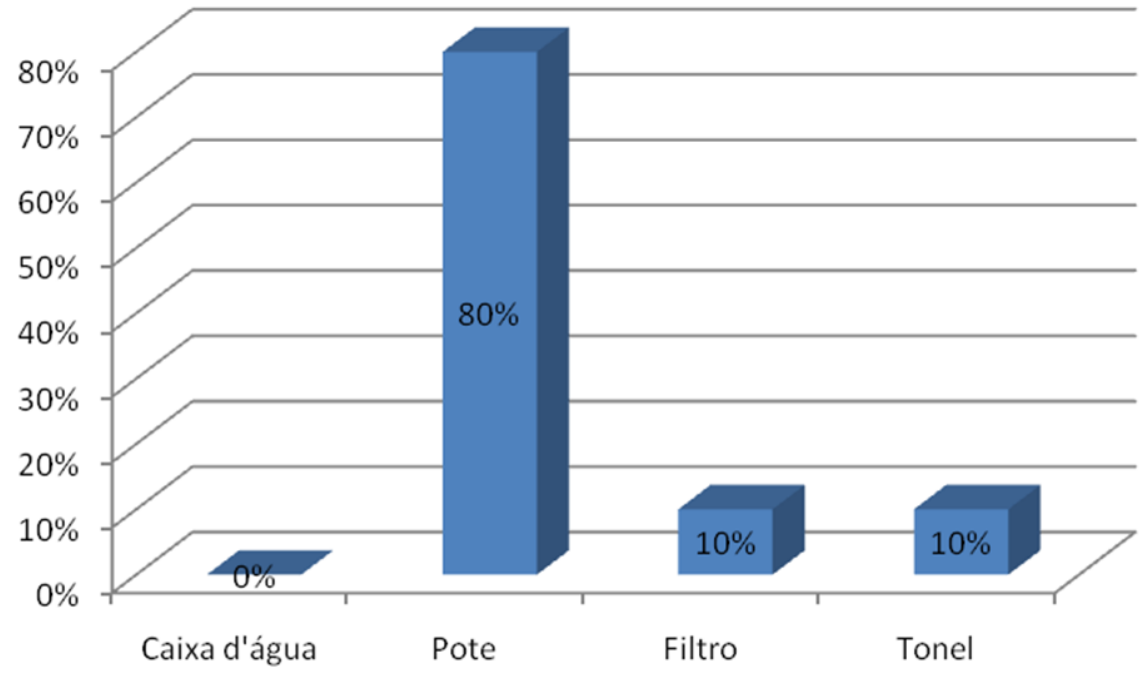

Figura 5 - Armazenamento da água de beber

Segundo os agricultores, (80\%) da população dos assentamentos Frei Damião e Santo Antônio utilizam o simples acondicionamento em pote como a principal forma de reservatório da 
água utilizada para beber. Ao preservareste hábito de armanezamento da água, incorre-se em risco de contaminação da mesma, pois muitas vezes se faz uso de copos e mãos sem a adequada higienização.

A água de chuva armazenada nas cisternas por longos períodos onde diariamente se introduz o balde ou lata para retira-la, associada a práticas pouco higiênicas de captação de tetos, nem sempre limpos antes das chuvas, pode resultar em qualidade inadequada ao seu consumo direto, necessitando assim de algum tratamento (SILVA, 2006). Por isso, diversos trabalhos recomendam sua desinfecção antes do consumo (KATO, 2006).

Os resultados sobre a presença de tratamento na água de beber realizado pela população dos assentamentos Frei Damião e Santo Antônio são apresentados na Figura 6.

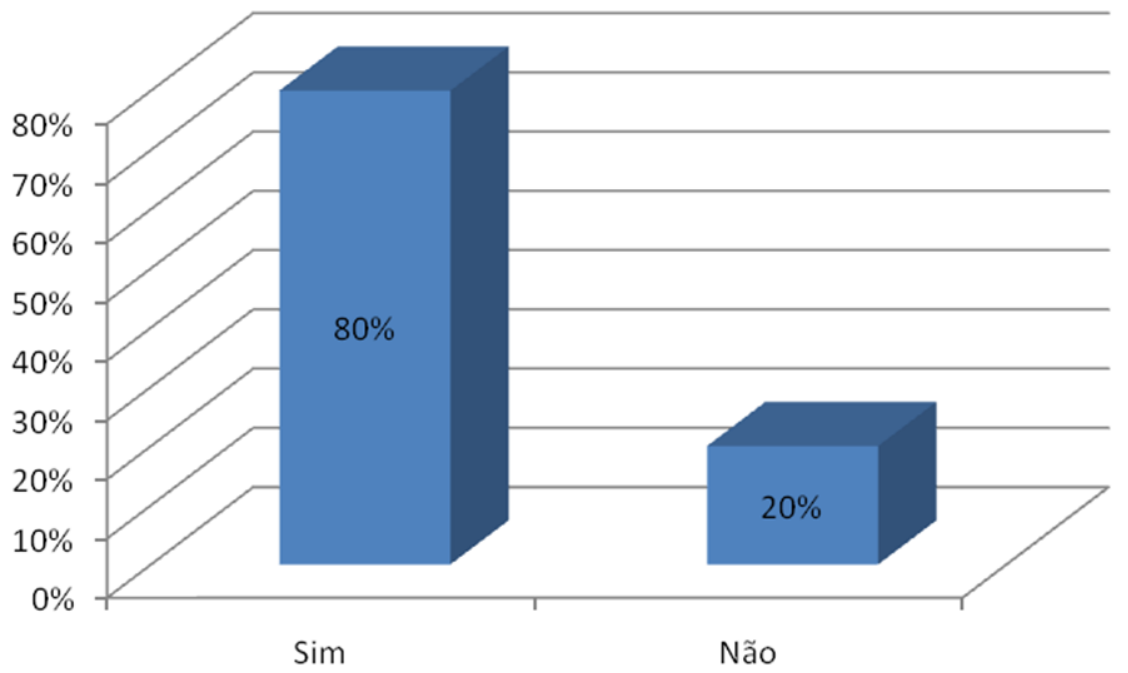

Figura 6 - Ocorrência de tratamento na água de beber realizado pela população dos assentamentos Frei Damião e Santo Antônio

Verifica-se que $80 \%$ dos agricultores realizam algum tipo de tratamento na água de beber. De acordo com Tavares (2009), o tratamento da água utilizada pela família é essencial tendo em vista que a utilização de água sem tratamento prévio promovem a veiculação de doenças infectocontagiosas conduzidas por via hídrica.

Segundo Botto (2007), 20\% da comunidade de Itaiçaba, no Estado do Ceará, não realizam nenhum tipo de tratamento doméstico de água. Logo após a etapa de sensibilização e oficinas na comunidade, houve um incremento de $3 \%$ nas famílias que tratavam água para consumo humano e após o trabalho dos multiplicadores, hoje, 100\% das famílias na comunidade Camurim tratam a água antes de consumi-la.

A Figura 7 ilustra o comportamento da população dos assentamentos Frei Damião e Santo Antônio no tocante as formas de tratamento das águas provenientes de cisternas. 


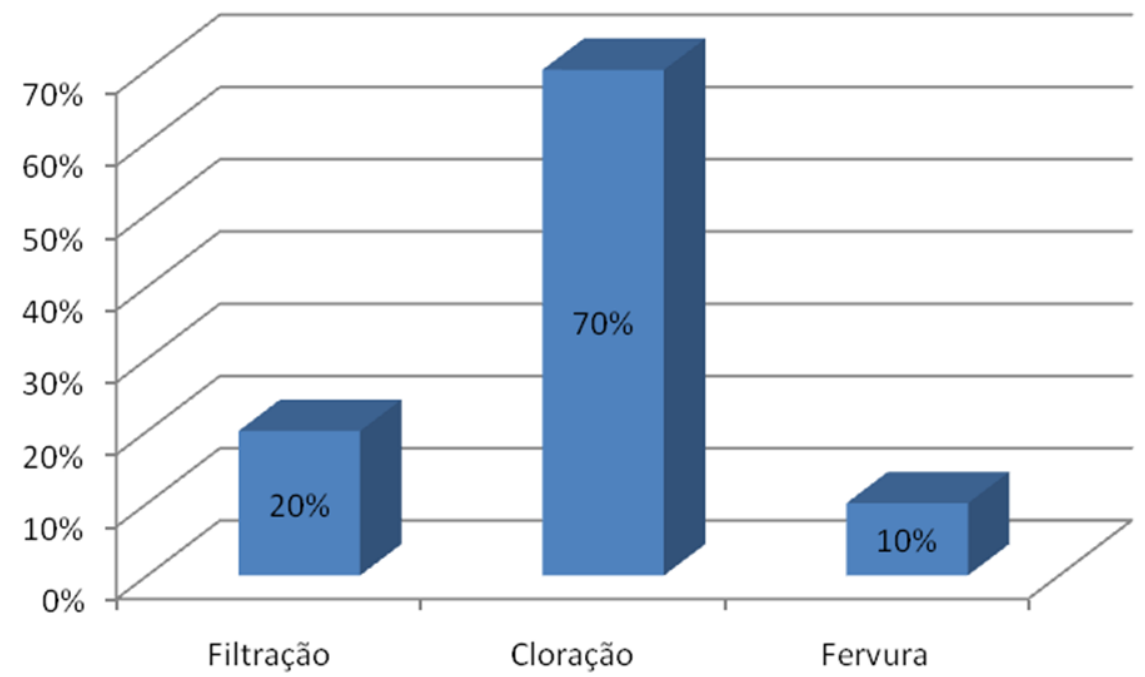

Figura 7 - Formas de tratamento

Dentre as técnicas de tratamento da água realizadas pelas famílias que tomam estes cuidados destaca-se a cloração (70\%). Tavares (2009) verificou que $87,4 \%$ da população pesquisada realiza algum tipo de tratamento de água com grande ênfase na cloração.

$\mathrm{Na}$ figura 8 são apresentados dados representativos da origem da água para higiene pessoal da população dos assentamentos Frei Damião e Santo Antônio.

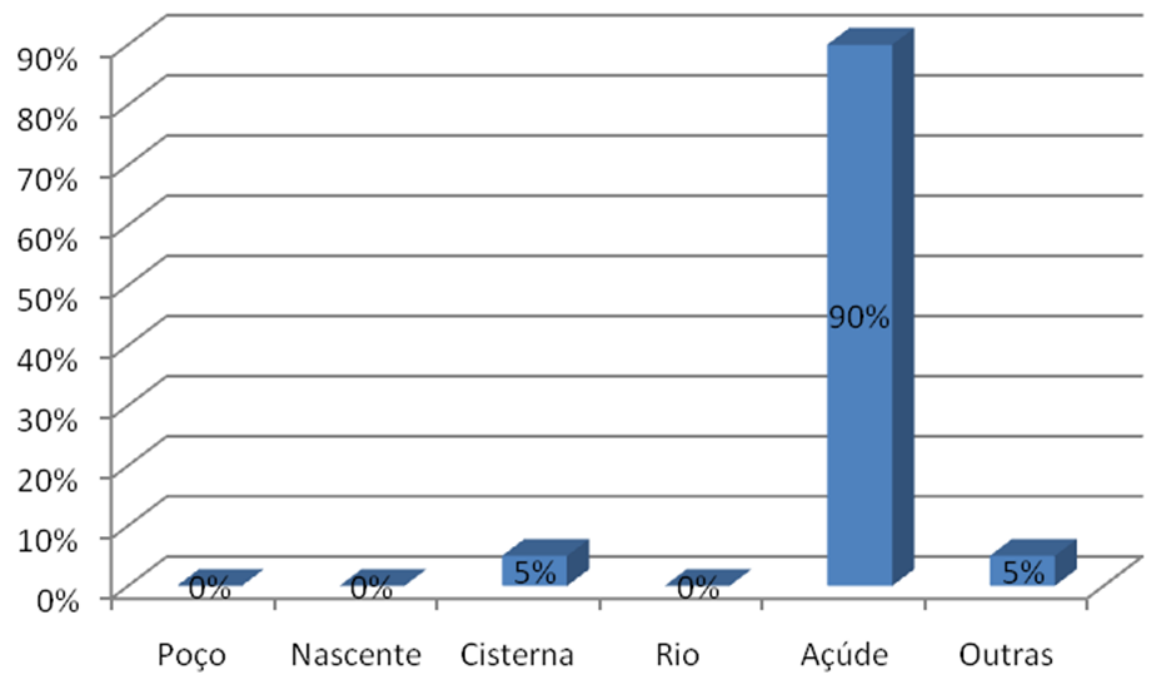

Figura 8 - Origem da água para higiene pessoal

De acordo com as respostas dos moradores $90 \%$ dos agricultores utilizam água de açúde para realizarem a higiene pessoal. No armazenamento desta água são utilizados Caixa d'água (70\%), cisterna (20\%) e tonel (10\%). De acordo com Brasil (2006) existem diversos grupos de doenças relacionadas a água utilizada na higiene pessoal, sejam doenças relacionadas as condições de abastecimentos ou enfermidades de ocorrência ligada diretamente ao meio hídrico a exemplo das verminoses. 
A Figura 9 esboça a distribuição dos dados de uso de água de cisternas da população dos assentamentos Frei Damião e Santo Antônio.

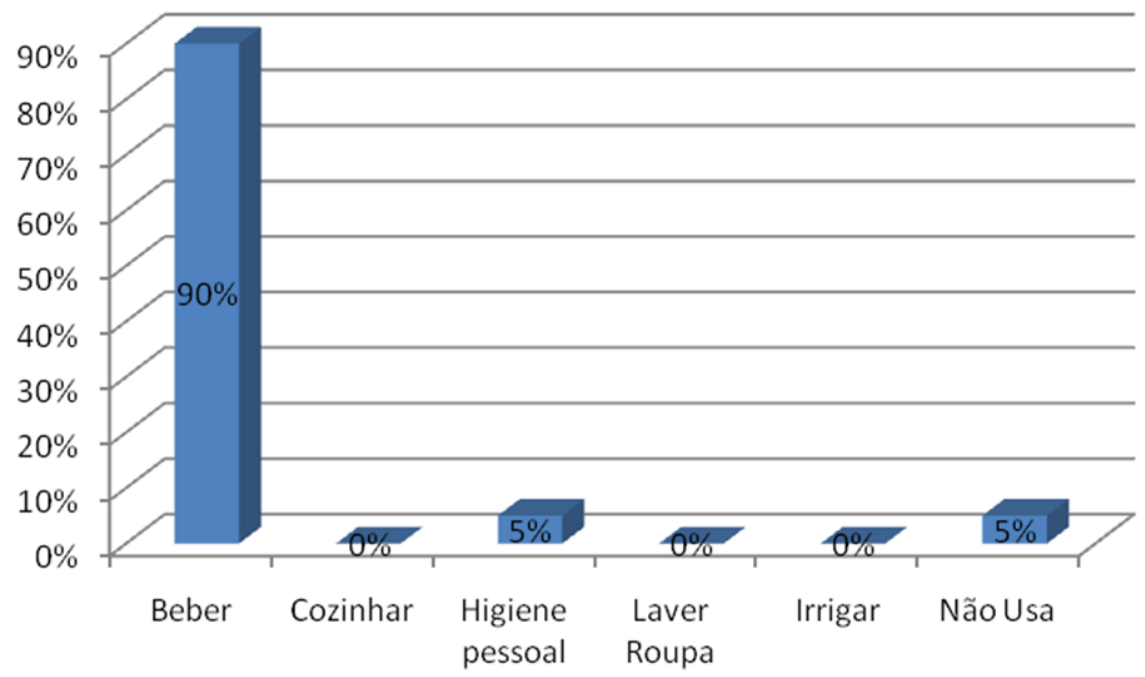

Figura 9- Usos da água da cisterna

Segundo os entrevistados (90\%) a água da cisterna é utilizada para beber. Santos (2008) verificou que $87,5 \%$ da população pesquisada utilizam a água da cisterna para beber e cozinhar. Para ela a água da chuva geralmente apresenta-se de boa qualidade para consumo humano, com exceção para locais com alta poluição atmosférica, altamente povoadas ou industrializadas, fazendo-se necessário a adoção de mecanismos de desinfecção para que haja fornecimento de água de boa qualidade para beber.

A figura 10 ilustra a classificação das informações obtidas da população dos assentamentos Frei Damião e Santo Antônio, no tocante a determinação se a água de cisterna é de boa qualidade.

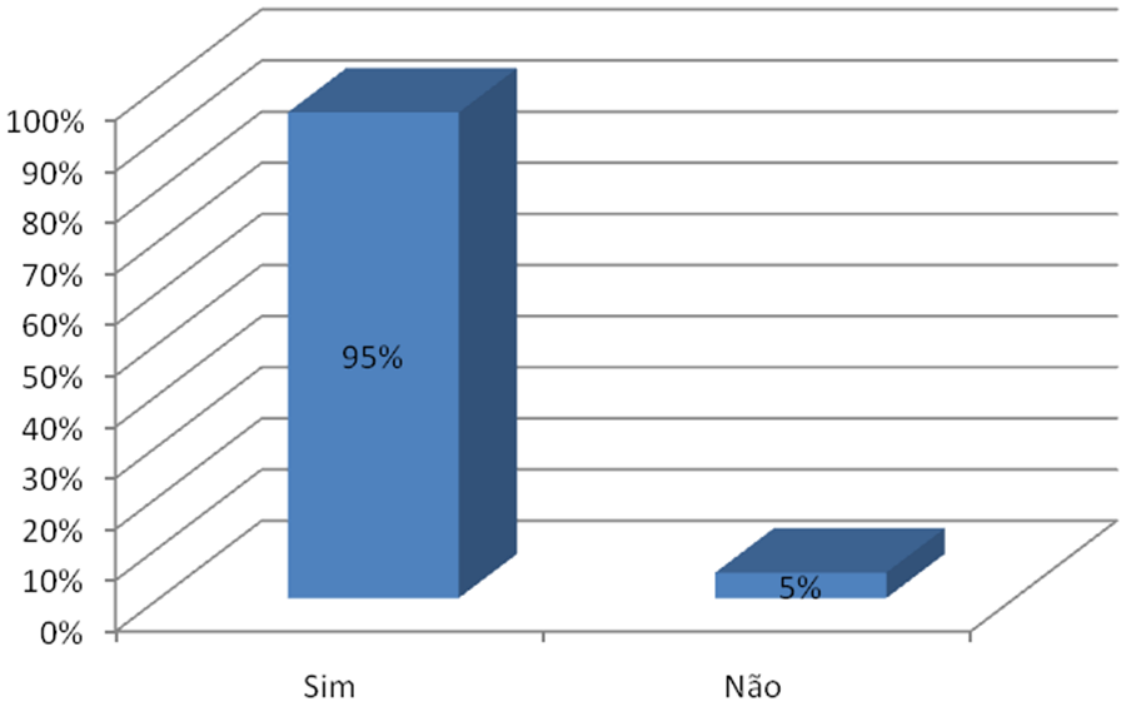

Figura 10 - A água da cisterna é de boa qualidade 
De acordo com os resultados, os agricultores (95\%) consideram a água da cisterna de boa qualidade para o consumo humano. As famílias que utilizam a água da cisterna para beber afirmaram que as condições de saúde melhoraram após a utilização da água acumulada na cisterna. Estes resultados estão de acordo com os resultados encontrados por Pontes (2011), realizando pesquisa no Vale do Pajeú em Pernambuco, 73\% dos entrevistados consideraram ruim a qualidade da água antes da construção das cisterna. De acordo com Razzolini e Günther (2008) o fornecimento de água de qualidade em comunidades rurais é essencial, tendo em vista que geralmente estas comunidades estão sujeitas as situações de risco relacionadas à saúde, tanto individual como coletiva.

Os resultados da pesquisa realizada com a população dos assentamentos Frei Damião e Santo Antônio, referente à suficiência da água de cisterna para o ano todo estão apresentados na Figura (11).

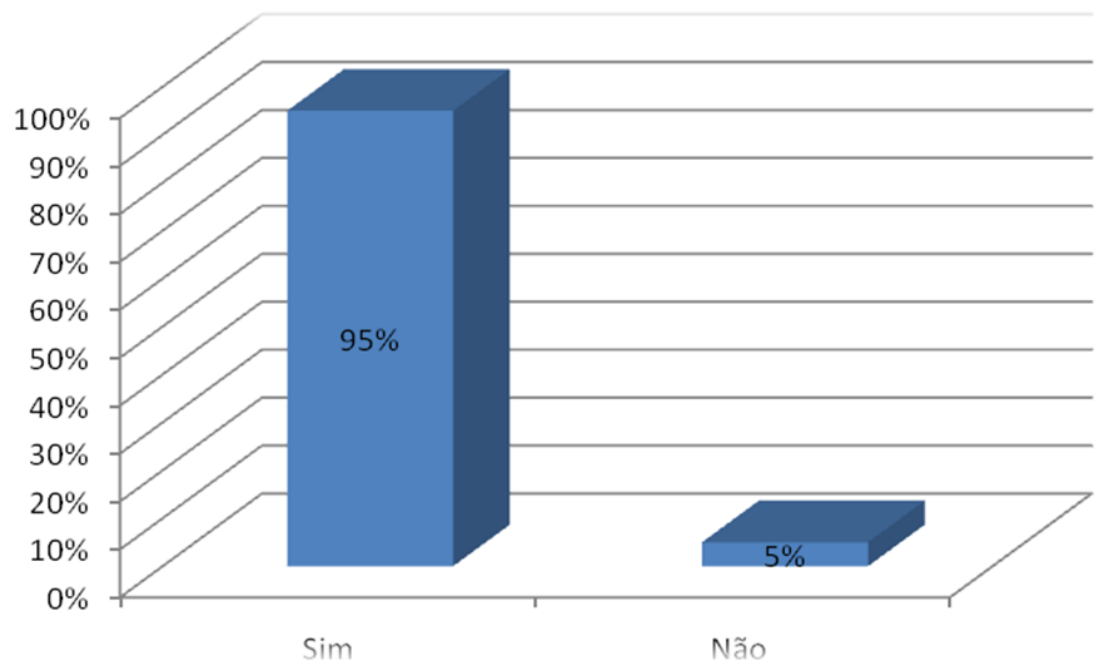

Figura 11 - A água da cisterna é suficiente para o ano todo

Todas as cisternas dos assentamentos pesquisados foram construídas com recursos do governo federal, especificamente o "Programa de Formação e Mobilização para Convivência com - Semiárido: Um Milhão de Cisternas Rurais (P1MC)". De acordo com as respostas dos entrevistados $95 \%$ das agricultores responderam que a água da cisterna é suficiente para o uso exclusivo para beber durante todo o ano, este fato está relacionado diretamente a quantidade de pessoas da família. Tendo em vista que as cisternas com capacidade de 16000 litros de água é suficiente para uma família de 5 pessoas utilizar para beber dutante o período de estiagem e nesta pesquisa foi observado que a média de pessoas por família é de 4,5 pessoas. Estes dados estão em desacordo com Brito et al. (2005), em pesquisa realizada em Petrolina - PE, verificaram que $98 \%$ dos agricultores afirmaram que a água armazenada na cisterna é insuficiente para atender as necessidades da família durante o período da estiagem.

Segundo Tavares (2009) o fato da água faltar no período da estiagem dar-se devido ao uso inadequado dessas águas, tendo em vista que a água da cisterna deveria ser usada exclusivamente para beber, cozinha e higienização pessoal. Outra causa sugerida pelo autor é o fato de que as cisternas foram desenvolvidas para atender famílias de até cinco pessoas, se a família possui um número superior a cinco certamente influenciará na falta de água especialmente em períodos de estiagem.

Santos e Silva (2009), em pesquisa realizada em Sergipe sobre cisternas, relatam que a maioria dos entrevistados, $74,19 \%$, considerou a captação da água de chuva muito importante e 
que a qualidade de vida deverá melhorar porque gerou a expectativa de que a água armazenada será suficiente para o suprimento de água durante o período de estiagem. $96,77 \%$ dos entrevistados demonstraram satisfação com a utilização dos sistemas de captação de água, assim como com as ações desenvolvidas pelo P1MC.

A figura 12 esboça a distribuição de frequência com que a população dos assentamentos Frei Damião e Santo Antônio realiza limpeza da cisterna e do sistema de coleta de água.

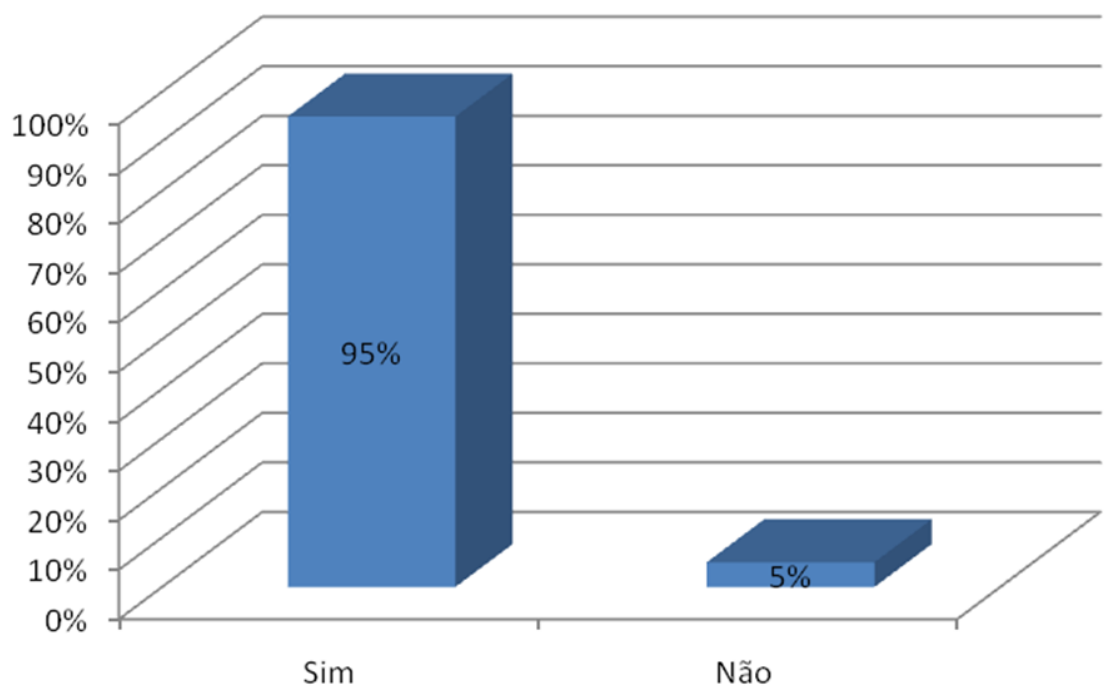

Figura 12 - Realiza limpeza da cisterna e do sistema de coleta de água?

A maioria dos agricultores (95\%) realizam limpeza das cisternas e dos sistemas coletor de água (calhas, canos, etc), quanto a frequência eles realizam esta limpeza anualmente.

Segundo Tomaz (2003) a qualidade da água de chuva pode ser encarada em quatro etapas: a) antes de atingir o solo; b) após escorrer pelo telhado; c) dentro do reservatório; 4) no ponto de uso.

A figura 13 representa a classificação de assiduidade com que a água da primeira chuva (considerada água de qualidade duvidosa) vai para cisterna.

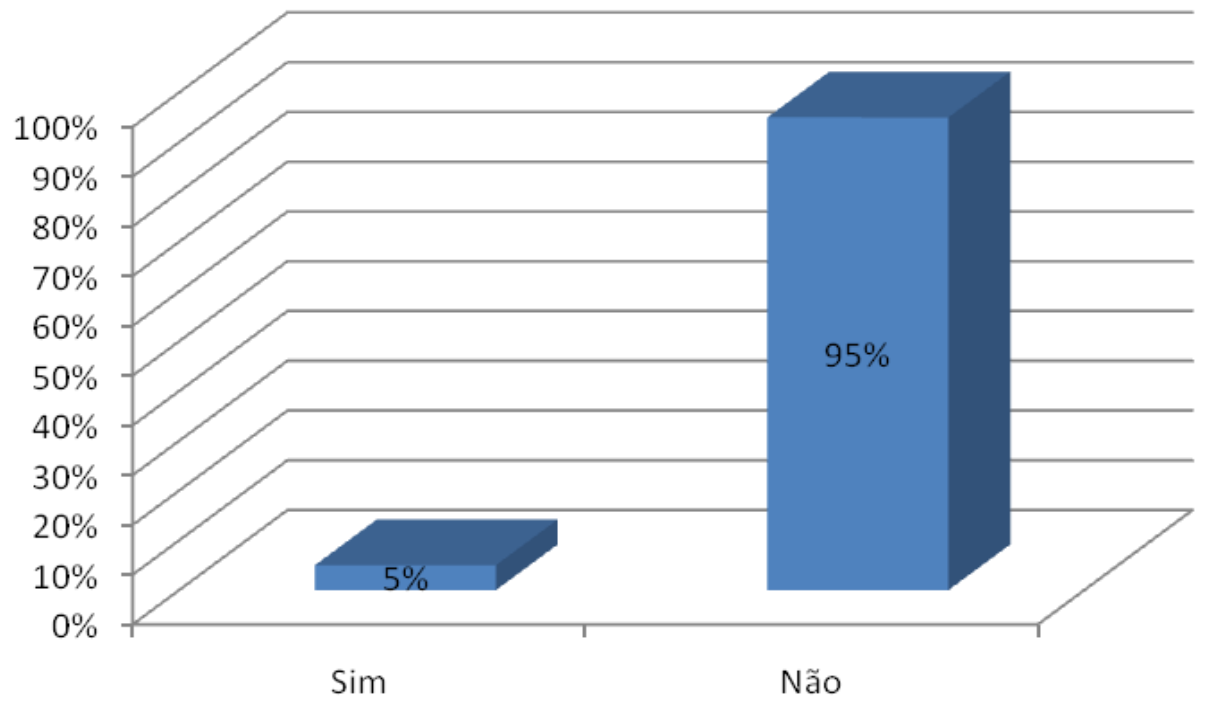

Figura 13 - A água da primeira chuvai vai para a cisterna 
Outra barreira sanitária eficiente para manter a qualidade da água armazenada na cisterna é a eliminação das águas das primeiras chuvas. Segundo Tavares (2009), a adoção de ações como esta favorece a redução da contaminação da água.

Conforme o Manual de Saneamento divulgado pela Fundação Nacional de Saúde (FUNASA) devem-se abandonar as águas das primeiras chuvas, pois lavam os telhados onde se depositam a sujeira proveniente de pássaros animais e poeira. Para evitar que essas águas caiam na cisterna, o manual sugere que desconectem os tubos condutores de descida, que normalmente devem permanecer desligados para serem religados manualmente, pouco depois de iniciada a chuva. Existem dispositivos automáticos que permitem o desvio, para fora das cisternas, das águas das primeiras chuvas e das chuvas fracas, aproveitando-se, unicamente, as das chuvas fortes (FUNASA, 1999).

Na figura 14 está representada a forma como a população dos assentamentos Frei Damião e Santo Antônio extraem a água da cisterna.

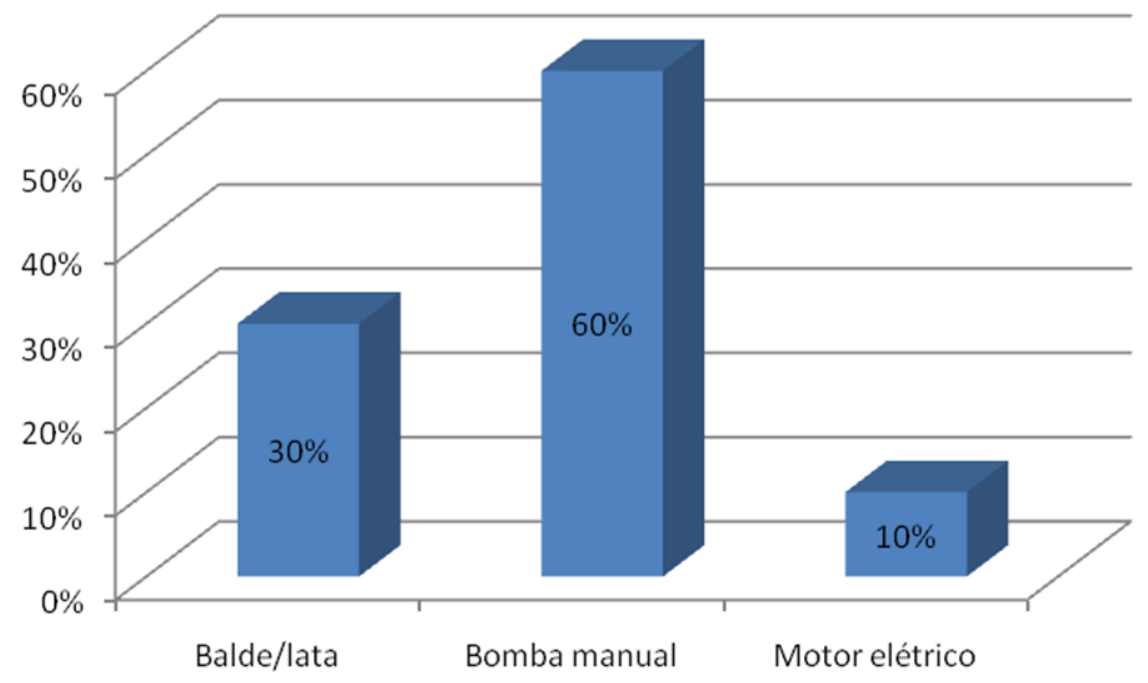

Figura 14 - Como ocorre a extração da água da cisterna

De acordo com as respostas dos entrevistados $60 \%$ dos agricultores utilizam bomba manual para a retirada da água da cisterna. Quanto ao uso de latas ou baldes para a retirada da água todos aqueles que usam este procedimento afirmaram que usam o balde apenas para este fim. De acordo com Xavier (2010), esta é uma relevante barreira sanitária, pois impede que o morador tenha contato direto com a água acumulada. A utilização do balde ou lata para retirada da água da cisterna ou para conduzir para o interior da casa deve ser feita de forma criteriosa, tendo em vista que este transporte é um importante fator de contaminação. Tendo em vista que muitas vezes estes objetos são guardados de forma inadequada.

Todas as pessoas pesquisadas afirmaram que tomam cuidados para evitar a entrada de sujeira no interior da cisterna. Para aqueles que utilizam a água da cisterna para beber consideram que com a implantação das cisternas as doenças que as pessoas freqüentemente acometidas (diarréia, verminose), diminuíram significativamente após a adoção da cisterna.

Entre as razões que motivaram os agricultores a adotarem as cisternas de placas como reservatório de água de qualidade para o consumo humano está a iniciativa do Programa Um milhão de Cisternas (P1MC), além disso, os agricultores viram nesta iniciativa a oportunidade de 
dispor de água de qualidade no período de estiagem. Os agricultores destacam que com a utilização da água da cisterna reduziu significativamente a pressão no uso de água dos pequenos açudes localizados nos assentamentos.

Carlon (2005) constatou em um trabalho em Joinville-SC, que as razões citadas pelos entrevistados que justificariam a implantação das cisternas para aproveitamento de água da chuva em Joinville são: o grande volume de chuvas que atingem a região (37\%); a água de chuva como sendo uma fonte alternativa de água (23\%); a redução no consumo de água tratada em função de ter uma fonte extra (20\%); a preservação dos mananciais que não seriam superexplorados (13\%) e o controle das enchentes evitando que grandes volumes de água chegasse as galerias pluviais (7\%).

O desperdício é apontado hoje como um dos principais inimigos a serem combatidos, visto que a população de um modo geral não dá o devido valor ao líquido da vida, prevalecendo à ilusão de um bem inesgotável. Talvez um fator que contribua para este descaso da população, além da falta de consciência e educação sobre a proteção dos recursos hídricos, seja o baixo custo comparativamente a outros produtos do mercado.

Uma ação preventiva de educação ambiental é crucial para evitar as medidas dispendiosas subseqüentes para reabilitar, tratar e desenvolver novas fontes de água. Rever hábitos dos indivíduos e da coletividade, não é uma tarefa fácil. Daí a importância de investir na nova geração, nos jovens e crianças, pois, é através da educação que se formam cidadãos conscientes.

\section{CONSIDERAÇÕES FINAIS}

Muitos países do mundo, por diversos motivos, já sofrem com a escassez de água doce, neste sentido o Brasil precisa adotar cada vez mais políticas públicas no sentido de potencializar a captação de água de chuva para abastecimento humano e implementar programas de educação ambiental capazes de promover o uso sustentável da água. Garantindo assim acesso à água de qualidade e consequentemente promovendo melhorias nos índices sociais e econômicos. Assim, pode-se verificar que as pessoas dos assentamentos pesquisados estão satisfeitas com a qualidade da água de suas cisternas, a água acumulada nas cisternas são utilizadas exclusivamente para beber, todas possuem acesso a água encanada (para higiene pessoal e cozinhar) proveniente de um açude, mas esta água não passa por nenhum tratamento. Apresentam em geral um manejo adequado na retirada da água da cisterna, possuem conhecimento a cerca das barreiras sanitárias para evitar a contaminação da água e se preocupam em adotar mecanismos para evitar a entrada de sujeira no interior das cisternas.

\section{REFERÊNCIAS BIBLIOGRÁFICAS}

1. BEZERRA, M. N.; SILVA, C. G. da; BARROS, R. P. de. Melhorias no uso sustentável da água no semi-árido e a tecnologia decisternas em Girau do Ponciano -AL. Arapiraca-AL. Anais... Arapiraca: UNEAL, 2010.

2. BOTTO, M. P. Avaliação da viabilidade técnico e social da desinfecção solar (sodis) em águas de cisternas de placa - estudo de caso camurim (itaiçaba). In: $6^{\circ}$ Simpósio Brasileiro 
de Captação e Manejo de Água de Chuva. Belo Horizonte, MG. Anais. Belo Horizonte: 2007.

3. BRASIL. Ministério da Saúde. Secretaria de Vigilância em Saúde. Vigilância e controle da qualidade da água para consumo humano. Brasília : Ministério da Saúde, 2006. 212 p

4. BRITO, L. T. de L.; PORTO, E. R.; SILVA, A. de S.; SILVA, M. S. L. da; HERMES, L. C; MARTINS, S. S. Avaliação das características físico-químicas e bacteriológicas das águas de cisternas da comunidade de Atalho, Petrolina-PE. In: $5^{\circ}$ Simpósio Brasileiro de Captação e Manejo de Água de Chuva. Teresina, PI. Anais... Teresina: ABCMAC, 2005.

5. CARLON, M. R. Percepção dos atores sociais quanto as alternativas de implantação de sistemas de captação e aproveitamento de água de chuva em Joinville - SC. 2005. 203f. Dissertação (Mestrado Acadêmico em Ciência e Tecnologia Ambiental)- Universidade do Vale do Itajaí, Itajaí, SC, 2005.

6. FUNASA, Fundação Nacional de Saúde. Manual de saneamento, cap. 2, p. 59-62. Brasília: Ministério da Saúde, 1999. p. 54-57. Disponível em: 167 <http://www.funasa.gov.br/sitefunasa/pub/manusane/manusan00.htm>. Acesso em: 03 maio. 2011. Arquivo em formato pdf.

7. KATO, M.T. Qualidade de águas de cisternas utilizadas para fins de consumo humano no município de Poço Redondo - SE. In: SEMINARIO INTERNACIONAL DE ENGENHARIA DE SAUDE PUBLICA SANEAMENTO AMBIENTAL SUSTENTABILIDADE E INCLUSAO, 3.,2006. Fortaleza-CE. Anais... Fortaleza, 2006.

8. NEVES, R. S.; MEDEIROS, J. C. de A.; SILVEIRA, S. M. B.; MORAIS, C. M. M. Programa Um Milhão de Cisternas: guardando água para semear vida e colher cidadania. Revista Agriculturas, v. 7, n. 3, p. 7-11, 2010.

9. OlTRAMARI, A. C.; ZOLDAN, P.; ALTMANN, R. Agricultura orgânica em SantaCatarina. Florianópolis: Instituto Cepa, 2002. 55p.

10. PONTES, E. T. M. Avaliação de uma experiência de convivência com o semiárido no Vale do Pajeú, Pernambuco. Revista Scientia Plena, v. 7, n. 4, p. 1-16, 2011.

11. PONTES, E. T. M.; MACHADO, T. A. Programa um milhão de cisternas rurais no nordeste brasileiro: políticas públicas, desenvolvimento sustentável e convivência com o semiárido. In: XIX Encontro Nacional de Geografia Agrária. São Paulo, SP. Anais... São Paulo: USP, 2009.

12. RAZZOLINI, M. T. P.; GÜNTHER, W. M. R. Impactos na Saúde das Deficiências de Acesso a Água. Revista Saúde e Sociedade, v.17, n.1, p.21-32, 2008.

13. SANTOS, M. A. F. dos. Qualidade da água de chuva armazenada em cisternas rurais e as modificações decorrentes do manuseio na região de Serrinha-BA. 2008. 71 f. Dissertação 
(Mestrado em Ciências em Engenharia Civil e Ambiental) - Universidade Estadual de Feira de Santana. Feira de Santana, 2008.

14. SANTOS, M. J. dos; SILVA, B. B. da. Análise do modelo conceitual e tecnológico do programa cisternas rurais em Sergipe. Revista Engenharia Ambiental, v. 6, n. 2, p. 464483, 2009.

15. SILVA, C.V.da. Qualidade da água de chuva para consumo humano armazenada em cisternas de placa. Estudo de caso: Araçuaí, MG. 2006. Dissertacao (Mestrado em Saneamento, Meio Ambiente e Recursos Hidricos) - Escola de Engenharia da Universidade Federal de Minas Gerais, Minas Gerais - MG, 2006.

16. SILVA, E. L. da; MENEZES, E. M. Metodologia da pesquisa e elaboração de dissertação. Florianópolis: Laboratório de Ensino a Distância da UFSC, 2001. 121p.

17. SILVA, J. B. da; GUERRA, L. D.; GOMES, R. A.; FERNANDES, M. Ecologia política das cisternas de placas: uma abordagem sociológica das medidas governamentais recentes relativas aos problemas de abastecimento de água em comunidades rurais de Boa Vista e Montadas-PB. Revista Cronos, v. 10, n. 2, p. 121-143, 2009.

18. SILVA, M. M. P. da; OLIVEIRA, L. A. de; DINIZ, C. R.; CEBALLOS, B. S. O. Educação Ambiental para o uso sustentável de água de cisternas em comunidades rurais da Paraíba. Revista de Biologia e Ciências da Terra, v. esp., n. 1, p. 122-136, 2006.

19. TAVARES, A. C. Aspectos físicos, químicos e microbiológicos da água armazenada em cisternas de comunidades rurais no Semi-Árido paraibano. 2009. 166f. Dissertação (Mestrado em Desenvolvimento e Meio Ambiente) - Universidade Federal da Paraíba/ Universidade Estadual da Paraíba. Campina Grande - PB, 2009.

20. TOMAZ, P. Aproveitamento de água de chuva para áreas urbanas e fins não potáveis. São Paulo: Navegar Editora, 2003. ISBN: 85-87678-23-x

21. XAVIER, R. P. Influência de barreiras sanitárias na qualidade da água de chuva armazenada em cisternas no semiárido paraibano. 2010. 130f. Dissertação (Mestrado em Engenharia Civil e Ambiental) - Universidade Federal de Campina Grande. Campina Grande - PB, 2010.

22. VÁSQUEZ, S. F.; BARROS, J. D. de S.; SILVA, M. de F. P. da. Agricultura Orgânica: caracterização do seu produtor na cidade de Cajazeiras-PB. Revista Verde de Agroecologia e Desenvolvimento Sustentável, v.3, n.2, p 87-97, 2008. 